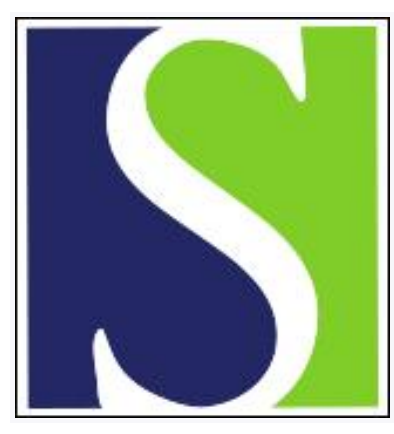

Scand J Work Environ Health 1996;22(4):311-314

https://doi.org/10.5271/sjweh.146

Issue date: Aug 1996

\title{
Allergic alveolitis in a school environment
}

by Thörn A, Lewné M, Belin L

Key terms: building-associated illness; case report; fungus; precipitating antibody; school health; sick-building syndrome

This article in PubMed: www.ncbi.nlm.nih.gov/pubmed/8881020

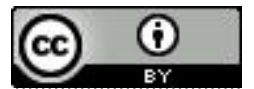




\title{
Allergic alveolitis in a school environment
}

\author{
by Åke Thörn, MD, ${ }^{1}$ Marie Lewné, MSc, ${ }^{2}$ Lars Belin, MD ${ }^{3}$
}

\begin{abstract}
Thörn Å, Lewné M, Belin L. Allergic alveolitis in a school environment. Scand J Work Environ Health 1996;
\end{abstract} $22: 311-14$

\begin{abstract}
Background A considerable fraction of newly constructed buildings have indoor air problems associated with health effects, usually of the nonspecific sick building syndrome variety. Specific health effects such as asthma, rhinitis, and allergic alveolitis can also occur.

Case On 1 September 1988 a school teacher showed symptoms of an acute respiratory illness, which was first interpreted as pulmonary embolism and then later as atypical sarcoidosis. The illness slowly progressed over six years, at which time the diagnosis was revised to chronic allergic alveolitis, related to her school environment. The school had had indoor-air quality problems off and on for several years.

Conclusions The case illustrates the difficulties of diagnosing cases of chronic allergic alveolitis, especially when it appears in environments where it is not generally encountered. It also raises questions regarding a possible relation between environments associated with the sick building syndrome and the occurrence of building-associated illnesses.
\end{abstract}

Key terms building-associated illness, case report, fungus, precipitating antibodies, sick building syndrome, school health.

Allergic alveolitis is an immunologically induced inflammation of the lung caused by continuous or repeated inhalation of various antigenic substances; organic dusts such as bacteria, molds and avian proteins and simple chemicals such as isocyanates $(1,2)$.

Clinically, two different syndromes of allergic alveolitis can be identified, the acute and the chronic form. The acute syndrome occurs in persons who are subjected to intense intermittent dust exposure. It consists of a sudden onset of influenza-like symptoms - fever, chills, malaise, nonproductive cough and severe dyspnea, starting 4 to $6 \mathrm{~h}$ after the exposure. The disease manifestations disappear within days if the causative dust is no longer inhaled.

The chronic form results from constant low-level exposure to an antigen. It starts insidiously with hardly any symptoms and gradually progresses, sometimes to severe disability, with increasing dyspnea, cough, fatigue, and often other nonspecific symptoms, such as anorexia, weight loss, subfebrile temperature and arthralgia $(1-4)$.

Usually, allergic alveolitis occurs in industrial or agricultural settings. It is commonly named after the occupational or environmental relations: wood trimmer's dis- ease, farmer's lung, pigeon-breeder's disease, hard metal disease, vineyard sprayer's lung, isocyanate lung (1, 2, $5-13)$. The syndrome also exists, however, in nonindustrial and nonagricultural environments, for example, offices, cafeterias, and homes (14-18). In this report, we describe a teacher who developed allergic alveolitis while working in a modern Swedish primary school.

\section{Case report}

A 34-year-old female school teacher at a suburban primary school became acutely ill with severe dyspnea on 1 September 1988. She was a nonsmoker and had never before had respiratory symptoms.

From a primary health center she was referred to a hospital, where an out-patient investigation was performed. Pulmonary embolism was suspected, but the diagnosis was never confirmed. Her condition improved, and she resumed work in the middle of October. Continuous dyspnea on exertion, cough, and a slightly raised body temperature $\left(37.5-37.8^{\circ} \mathrm{C}\right)$ led to a new medical investigation in the beginning of 1989 . The chest $\mathrm{X}$ rays showed discrete, bilateral, interstitial pulmonary infiltra-

1 Unit for Occupational Medicine, County Hospital, Boden, Sweden.

2 Clinic of Occupational Medicine, Karolinska Hospital, Stockholm, Sweden.

3 Asthma and Allergy Research Center, Department of Medicine, Sahlgrenska Hospital, Göteborg, Sweden.

Reprint requests to: Dr Åke Thörn, Yrkesmedicinska Enheten, Bodens Sjukhus, S-961 85 Boden, Sweden. 
tions. Spirometry revealed a restrictive ventilation defect with a forced expiratory volume in $1 \mathrm{~s}\left(\mathrm{FEV}_{1.0}\right)$ of 1.91 and a forced vital capacity (FVC) of 2.051 . The lung diffusion capacity, measured by the single breath technique (CO), was reduced to $0.95 \mathrm{mmol} \cdot \mathrm{min}^{-1}$. $\mathrm{kPa}^{-1} \cdot 1^{-1}$, corresponding to $45 \%$ of the predicted value. Kveim's test was positive, and the concentration of ACE (angiotension-converting enzyme) was pathologically high. The Mantoux test was negative. Bronchoalveolar lavage showed lymphocytosis in the lavage fluid. After these findings the diagnosis was revised to atypical sarcoidosis.

The patient continued teaching at the school with a $25 \%$ reduction of a full-time work schedule. Her body temperature normalized, but she still had dyspnea on exertion and cough, worse in the supine position and if exposed to combustion exhaust and cold air. She suffered from fatigue, but never had anorexia, weight loss, or joint or muscle aches.

In the course of time the patient's dyspnea gradually progressed. In May 1994 her condition worsened. A computed tomography scan of the lungs revealed interstitial fibrosis with an incipient honeycombing pattern. An open-lung biopsy showed a histopathological pattern of chronic, nonspecific pneumonitis. The $\mathrm{PaO}_{2}$ was very low, $6.0 \mathrm{kPa}$, and the patient had clubbings of the fingers. The immunoglobulin $\mathrm{E}$ (IgE) and the radioallergsorbant test (RAST) were normal. Precipitating antibodies against Alternaria Tenuis, Aspergillus Fumigatus, Botrytis Cinerea, Cladosporium Herbarum, Penicillium Notatum, Pullullaria Pullulans, and Rhizopus Rhizopodiformis were found when the patient's serum was tested against a panel of molds using the double immunodiffusion method of Ouchterlony.

With these findings the diagnosis was revised to be allergic alveolitis. Initially she was given prednisolone in a daily dose of $60 \mathrm{mg}$ initially, and $30 \mathrm{mg}$ for continuation. She was also referred to an occupational health clinic. The discoveries of precipitating antibodies were confirmed at a second laboratory, with the features of the analysis shown in figure 1.

During her summer vacation her condition improved, and her $\mathrm{PaO}_{2}$ increased to $8.4 \mathrm{kPa}$. On going back to school towards the end of August her dyspnea and cough worsened and the $\mathrm{PaO}_{2}$ decreased to $7.2 \mathrm{kPa}$. She has since been on medical restriction from the school and has improved somewhat.

\section{Environmental evaluation}

Patient's home. Since 1984 the patient has lived with her family in a suburban single family home built in 1968 . The house has no history of water damage of any sort, and there are no particular smells indoors. No humidifiers have been used. Air samples for molds were collected in January 1995 on sedimentation plates exposed for $20 \mathrm{~min}$ in the bedroom and kitchen. Normal numbers of colony-forming units (cfu) of Penicillium spores were found, $3 \mathrm{cfu}$ in the kitchen and $12 \mathrm{cfu}$ in the bedroom.

Patient's workplace. The patient's workplace is a primary school built in 1980 as a mechanically ventilated, onestory building, originally with a horizontal roof. There have been no humidifying devices connected to the ventilation or otherwise in the school, where the patient started to work in 1982 . Up to 1994 she has been working in three different classrooms, all located in the same area.

For energy saving reasons, the ventilation is not run nights and weekends. Up to 1989 no work activities occurred in the school during the summer, which is why the ventilation was turned off from June until the start of the fall semester around the 15th of August.

Since 1980 the school has had many problems resulting from water damage, mainly owing to repeated leakage through the roof, but also from plumbing. Its ventilation has been insufficient, and there have been many complaints of poor indoor air quality. The personnel (39 persons) have experienced, and still experience, diffuse

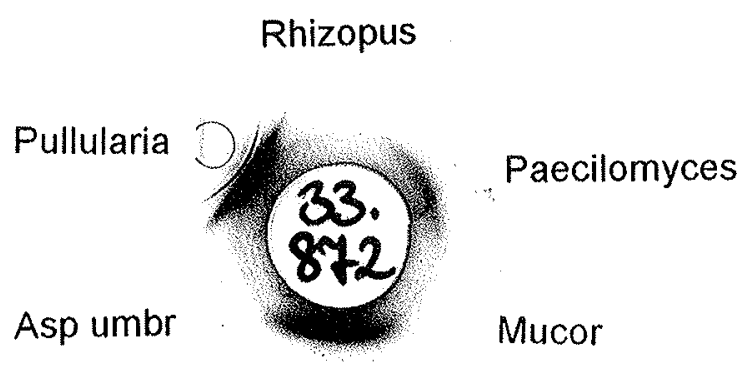

Asp fum

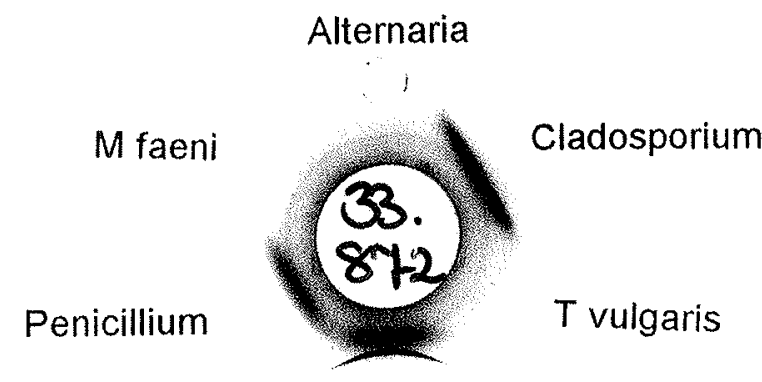

\section{Botrytis}

Figure 1. Photographs of the immunoanalysis of the patient's serum with a panel of microbial antigens as indicated in the figure. The figure shows positive reactions to Paecilomyces, Aspergillus fumigatus, Pullularia, Cladosporium, Botrytis and Penicillium species. 
symptoms, above all abnormal fatigue, and smells attributed to poor indoor air quality (figure 2). These symptom prevalences were obtained by using the Örebro MM questionnaires (19).

Because of these problems the local occupational health clinic has repeatedly investigated the building. In several classrooms, among them the patient's, it has found high water contents in the walls and floors, as well as somewhat increased concentrations of carbon dioxide $(800 \mathrm{ppm})$, as an indication of insufficient ventilation.

The roof was reconstructed in 1992. It was given an inclination to eliminate the permanent leakage problems. During the reconstruction period there was severe water damage, but after the completed reconstruction new damage has not been found. However, in both 1993 and 1994 the occupational health clinic detected an elevated water content in some floors. Most, but probably not all, of the water-damaged material, such as wall boards, had been removed by the beginning of 1995 .

Air samples for molds were collected in January 1995 on plates opened $20 \mathrm{~min}$ in the three classrooms where the patient had been working. No colony-forming units were detected.

\section{Discussion}

The diagnosis of a chronic form of allergic alveolitis is difficult mainly for the following reasons. First, there is a heterogeneous variety of exposures that can cause the condition, avian dust being the most common antigen in nonindustrial settings. Second, the time relation between a certain exposure and the onset of disease is often not obvious. Third, the disease manifestations are often very atypical. It is therefore important to have a high index of suspicion and consider allergic alveolitis in the differential diagnosis of all cases of interstitial lung disease.

Once suspected, the diagnosis is generally based on the following criteria: (i) no evidence of other diseases that could have caused the symptoms, (ii) characteristic symptoms including dyspnea and cough, (iii) radiographic findings, (iv) evidence of exposure to a relevant antigen, (v) precipitating antibodies, (vi) bronchoalveolar lavage with lymphocytosis, (vii) decreased oxygen tension of arterial blood, and (viii) restrictive impairment of lung function $(1-3,20-23)$.

Our patient satisfied the listed criteria, with the exception of clearcut evidence of exposure to an identified antigen. Her work environment has, however, suffered from long and repeated water damage. Parts of the walls and floors have been damaged by water on various occasions. These, as well as ventilation ducts during weekend and vacation breaks, may have served as moisture reservoirs for mold growth.

Retrospectively, it was realized that the patient's symptoms worsened regularly every August on returning

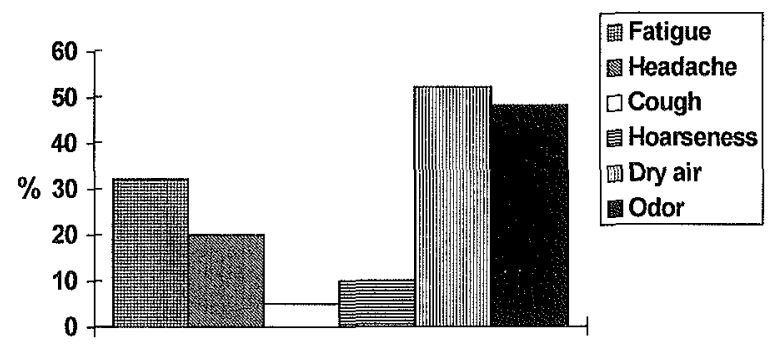

Figure 2. Prevalence of the sick-building syndrome symptoms among the employees $(N=39)$ of the case school.

to school after summer vacation. She had strong positive tests for precipitating antibodies against several mold species, indicating an exposure sufficient to generate a very evident immunologic response. These serological data, together with the clinical and laboratory findings, suggested the diagnosis of allergic alveolitis and indicated the existence of causative mold antigens, probably in her school.

The onset of her illness was very acute on 1 September 1988 . We think that there could have been a massive growth (24) of molds in the ventilation ducts owing to water condensation or water leakage into the ducts during the long summer vacation break. Correspondingly large amounts of mold could have been released into the indoor environment when the school (and the ventilation) started up again towards the end of August. In that manner the patient could have been suddenly and briefly exposed to large amounts of antigens, the result being the acute illness, which was later maintained by prolonged, continuous exposure, leading to chronic lung fibrosis.

During the last 20 years different medical symptoms linked to indoor air quality have frequently been identified in many buildings. A distinction has been made between the sick building syndrome and building-associated illness $(25,26)$. With the sick building syndrome there is an increased prevalence of symptoms from skin and mucous membranes, headache, fatigue, nausea, and dizziness among the occupants of the buildings. No specific diagnosis can be made. Laboratory and physical findings are usually normal. Building-associated illness, on the other hand, consists of different diseases with known etiologies and pathological alterations. Allergic alveolitis is one of these building-associated illnesses. The links between building-associated illness, such as allergic alveolitis, and sick building syndrome seem to be water and ventilation. Sick building syndrome does not depend on a single, unifying cause, but its occurrence is correlated with a great number of different factors, among them the building's type of ventilation and the condensation or the leakage of water $(27-29)$. Allergic alveolitis as a manifestation of building-associated illness, on the other hand, has specific etiologies, usually 
linked to obvious ventilation-based, wet microbial breeding-places, for example, humidifiers, air washers, heatercooler units, sump tanks (30). Our case demonstrates that it can also occur in buildings without such "wet" ventilation devices.

The World Health Organization estimates that $30 \%$ of newly constructed buildings show signs of sick building syndrome and that between $10 \%$ and $30 \%$ of the inhabitants suffer from symptoms (27). Allergic alveolitis as a building-associated illness is considerably more rare than sick building syndrome, but it has been shown that when it does occur, the prevalence of the nonspecific symptoms of the sick building syndrome is elevated too $(25,28,29)$. According to a survey done in 1994 at the case school (figure 2) sick building syndrome existed there. Complaints of symptoms attributed to poor indoor air quality had been filed for years. The symptoms of sick building syndrome are troublesome and interfere with life quality, but are not life-threatening. Sometimes there is a tendency to ignore them. However, when the prevalence of sick building syndrome in a building increases, the much rarer building-associated illness (29) also increases, which, as our patient demonstrates, is more serious. From a public health perspective it is therefore important to emphasize research on building-associated illness and sick building syndrome, as well as prevention and quick remedial action against leakage and water condensation in schools, kindergartens, nurseries, and other buildings.

\section{References}

1. Pitcher DW. Southwestern Internal Medicine Conference: hypersensitivity pneumonitis. Am J Med Sci 1990;300(4):25166.

2. Kaltreider HB. Hypersensitivity pneumonitis. West J Med 1993;159:570-8.

3. Walker CL, Grammer LC. Hypersensitivity pneumonitis. Allergy Proc 1993;14(2):137.

4. Salvaggio JE. Hypersensitivity pneumonitis; state of the art. Chest 1979;75(2):270-4.

5. Wimander K, Belin L. Recognition of allergic alveolitis in the trimming department of a Swedish sawmill. Eur J Respir Dis 1980;61 suppl 107:163-7.

6. Halpin DMG, Graneek BJ, Turner-Warwick M, Newman Taylor AJ. Extrinsic allergic alveolitis and asthma in a sawmill worker: case report and review of the literature. Occup Environ Med 1994;51:160 - 4 .

7. Halpin DMG, Graneek BJ, Lacey J, Nieuwenhuijsen, Williamsson PAM, Venables KM, Newman Taylor AJ. Respiratory symptoms, immunological responses and aeroallergen concentrations at a sawmill. Occup Environ Med 1994;51: $165-72$.

8. Malmberg P, Rask-Andersen A, Rosenhall L. Exposure to microorganisms associated with allergic alveolitis and febrile reactions to mold dust in farmers. Chest 1993;103:1202 -9.

9. Rask-Andersen A, Land CJ, Enlund K, Lundin $\AA$. Inhalation fever and respiratory symptoms in the trimming department of
Swedish sawmills. Am J Ind Med 1994:25:65-7.

10. Emanuel DA, Kryda MJ. Farmer's lung disease. Clin Rev Allergy 1983;1:509-32.

11. Bourke SJ, Banham SW, Carter R, Lynch P, Boyd G. Longitudinal course of extrinsic allergic alveolitis in pigeon breeders. Thorax 1989;44:415-8.

12. Carlson JE, Villaveces JW. Hypersensitivity pneumonitis due to pyrethrum: report of a case. JAMA 1977;237(16):1718 - 9.

13. Vandenplas O, Malo J-L, Saetta M, Mapp CE, Fabbri LM. Occupational asthma and extrinsic alveolitis due to isocyanates: current status and perspectives. $\mathrm{Br} \mathrm{J}$ Ind $\mathrm{Med}$ 1993;50:213-28.

14. Hoffman RE, Wood RC, Kreiss K. Building-related asthma in Denver office workers. Am J Public Health 1993;83(1):89_ 93.

15. Hodgson MJ, Morey PR, Simon JS, Waters TD, Fink JN. An outbreak of recurrent acute and chronic hypersensitivity pneumonitis in office workers. Am J Epidemiol 1987;125(4):6318.

16. Hodgson MJ, Morey PR, Attfield M, Sorenson W, et al. Pulmonary disease associated with cafeteria flooding. Arch Environ Health 1985;40(2):96-101.

17. Hodgson MJ. Clinical diagnosis and management of buildingrelated illness and the sick-building syndrome. Occup Med 1989;4(4):593-606.

18. Park H-S, Jung K-S, Kim SO, Kim SJ. Hypersensitivity pneumonitis induced by Penicillum expansum in a home environment. Clin Exp Allergy 1994;24:383-5.

19. Andersson K, Fagerlund I, Stridh G, Larsson B. The MMquestionnaires: a tool when solving indoor climate problems. Örebro (Sweden): Department of Occupational and Environmental medicine, Örebro Medical Center Hospital, 1993.

20. Chiu A, Pegram S, Haponik EF. Hypersensitivity pneumonitis: a diagnostic dilemma. J Thorac Imaging 1993;8(1);6978.

21. Richerson HB, Bernstein IL, Fink JN, Hunninghake GW, Novey HS, Reed CE, et al. Guidelines for the clinical evaluation of hypersensitivity pneumonitis. J Allergy Clin Immunol $1989 ; 84: 839-44$

22. Richerson HB. Methods for survey and diagnosis. Am J Ind Med 1994;25:25-32.

23. Terho EO. Diagnostic criteria for farmer's lung disease. Am J Ind Med 1986;10:329.

24. Pasanen P, Pasanen A-L, Jantunen M. Water condensation promotes fungal growth in ventilation ducts. Indoor Air 1993; $3: 106-12$.

25. Welch LS. Severity of health effects associated with buildingrelated illness. Environ Health Perspect 1991;95:67-9.

26. Letz G A. Sick building syndrome: acute illness among office workers - the role of building ventilation, airborne contaminants and work stress. Allergy Proc 1990:11(3):109-16.

27. Lyles WB, Greve KW, Bauer RM, Ware MR, Schramke CJ, Crouch J, et al. Sick building syndrome. South Med J 1991: 84(1);65-76.

28. Kreiss $\mathrm{K}$. The epidemiology of building-related complaints and illness. Occup Med 1989:4(4):575-92,

29. Stolwijk JAJ. Sick-building syndrome. Environ Health Perspect 1991:95:99-100.

30. Bardana EJ, Montanaro A, O'Hollaren MT. Building-related illness: a review of available scientific data. Clin Rev Allergy 1988;6:61-89.

Received for publication: 21 August 1995 